\title{
Identification of essential oils with activity against stationary phase Staphylococcus aureus
}

Shuzhen Xiao ${ }^{1,2}$, Peng Cui ${ }^{2}$, Wanliang Shi ${ }^{2}$ and Ying Zhang ${ }^{2^{*}}$

\begin{abstract}
Background: Staphylococcus aureus is the most dominant human pathogen, responsible for a variety of chronic and severe infections. There is mounting evidence that persisters are associated with treatment failure and relapse of persistent infections. While some essential oils were reported to have antimicrobial activity against growing $S$. aureus, activity of essential oils against the stationary phase $S$. aureus enriched in persisters has not been investigated.
\end{abstract}

Methods: In this study, we evaluated the activity of 143 essential oils against both growing and stationary phase $S$. aureus by minimum inhibitory concentration (MIC) testing and by colony forming unit assay.

Results: We identified 39 essential oils (Oregano, Cinnamon bark, Thyme white, Bandit "Thieves", Lemongrass (Cymbopogon flexuosus), Sandalwood oil, Health shield, Allspice, Amyris, Palmarosa, Cinnamon leaf, Clove bud, Citronella, Geranium bourbon, Marjoram, Peppermint, Lemongrass, Cornmint, Elemi, Ho wood, Head ease, Lemon eucalyptus, Litsea cubeba, Myrrh, Parsley seed, Coriander oil, Dillweed, Hyssop, Neroli, Rosewood oil, Tea tree, Cajeput, Clove bud, Lavender, Sleep tight, Vetiver, Palo santo, Sage oil, Yarrow) at 0.5\% (v/v) concentration, 10 essential oils (Cinnamon bark, Oregano, Thyme white, Bandit "Thieves", Lemongrass, Sandalwood oil, Health shield, Allspice, Amyris, Palmarosa at 0.25\% (v/v) concentration, and 7 essential oils (Oregano, Cinnamon bark, Thyme white, Lemongrass, Allspice, Amyris, Palmarosa at $0.125 \%(\mathrm{v} / \mathrm{v})$ concentration to have high activity against stationary phase $S$. aureus with no visible growth on agar plates after five-day exposure. Among the 10 essential oils which showed high activity at 0.25\% (v/v) concentration, 9 (Oregano, Cinnamon bark, Thyme white, Bandit "Thieves", Lemongrass, Health shield, Allspice, Palmarosa, Amyris showed higher activity than the known persister drug tosufloxacin, while Sandalwood oil had activity at a higher concentration. In Oregano essential oil combination studies with antibiotics, Oregano plus tosufloxacin (or levofloxacin, ciprofloxacin) and rifampin completely eradicated stationary phase S. aureus cells, but had no apparent enhancement for linezolid, vancomycin, sulfamethoxazole, trimethoprim, azithromycin or gentamicin.

Conclusions: Our findings indicate that some essential oils have excellent activity against both growing and stationary phase S. aureus. Further studies are needed to identify the active components, evaluate safety, pharmacokinetics, and their activity to eradicate $S$. aureus infections in vivo.

Keywords: Staphylococcus aureus, Stationary phase, Essential oils, Antimicrobial activity

\footnotetext{
* Correspondence: yzhang@jhsph.edu

${ }^{2}$ Department of Molecular Microbiology and Immunology, Bloomberg School of Public Health, Johns Hopkins University, Baltimore, MD 21205, USA

Full list of author information is available at the end of the article
} 


\section{Background}

Staphylococcus aureus is the leading cause of nosocomial and community-associated infections, which is responsible for a wide variety of infections that include mild superficial skin infections, osteomyelitis, implantassociated heart valve, native valve endocarditis, severe sepsis and bacteremia [1]. If infections caused by $S$. aureus are not effectively treated, high mortality in some patients could occur [2]. Although antibiotic resistance is a major problem in treatment of infections caused by $S$. aureus, drug-tolerant persisters such as small colony variants ( $\mathrm{SCVs}$ ) are demonstrated to be significant contributors of chronic persistent infections and recurrent infections [3]. Persisters are non-growing or slow growing antibiotic-tolerant bacterial cells that are able to revert to growing forms under appropriate conditions and cause relapse or persistent infections with symptoms $[4,5]$. Clinically, infections caused by $S$. aureus such as soft tissue infections, endocarditis, osteomyelitis, prosthetic joint infections, and biofilmrelated infections on indwelling device is difficult to cure with the current antibiotics, which are mainly active against the growing bacteria but have poor activity against the non-growing persisters [6]. Recently, it has been shown that a drug combination approach using drugs targeting both log phase growing bacteria and the non-growing stationary phase bacteria could more effectively eradicate a persistent urinary tract infection and a biofilm skin infection in the mouse models [4, 79]. However, the choice of persister drugs is limited at present, and treatment of persistent infections remains a challenge.

Essential oils are concentrated volatile liquids extracted from plants. They are widely used in food processing, aromatherapy and also in medical therapy especially with recent concerns on anti-bacteria activity [10]. Many studies reveal that essential oils have antibacterial activity against both Gram-negative and Grampositive bacteria [11]. In addition, various compositions of essential oils including eugenol, carvacrol and thymol have been demonstrated to be active against different bacterial species [12]. Although some essential oils were found to be active against growing $S$. aureus $[11,13,14]$, the activity of essential oils against non-growing stationary phase $S$. aureus has not been studied. Because activity against non-growing persisters or stationary phase bacteria correlates with in vivo activity against persistent infections in the case of uropathogenic $E$. coli and $B$. burgdorferi persistent infections [7, 9, 15, 16], here, we evaluated a panel of 143 essential oils for their activity against stationary phase $S$. aureus as a model for activity against persisters $[6,17]$. We identified a range of highly potent essential oils with excellent activity against nongrowing stationary phase $S$. aureus.

\section{Methods}

\section{Bacterial strain and culture conditions}

$S$. aureus strain Newman, a commonly used pansusceptible strain isolated from a patient suffering from osteomyelitis [6], was used in this study. The strain was grown in Tryptic Soy Broth (TSB) medium without shaking at $37^{\circ} \mathrm{C}, 5 \% \mathrm{CO}_{2}$ overnight and the culture was regarded as stationary phase $S$. aureus culture according to our previous study [6]. The overnight stationary phase $S$. aureus culture $\left(\sim 10^{9} \mathrm{CFU} / \mathrm{mL}\right)$ was used directly without dilution for essential oil screens and drug exposure tests.

\section{Antibiotics and essential oils}

Tosufloxacin, ciprofloxacin, levofloxacin, rifampin, linezolid, vancomycin, sulfamethoxazole, trimethoprim, azithromycin and gentamicin were purchased from SigmaAldrich (St. Louis, MO, USA) and dissolved in dimethyl sulfoxide (DMSO) or $\mathrm{H}_{2} \mathrm{O}$ to form $10 \mathrm{mg} / \mathrm{mL}$ or 100 mM stock solutions $[3,9,10]$. All antibiotic stocks (except DMSO stocks) were filter-sterilized by $0.2 \mu \mathrm{m}$ filter and stored at $-20^{\circ} \mathrm{C}$.

Commercially available essential oils were purchased from Natural Acres (MO, USA), Plant Therapy (ID, USA) and Plant Guru (NJ, USA). More information about the essential oils can be found on their websites (http://www.theplantguru.com/gc-ms-testing, http:// www.planttherapy.com/essential-oils, http://naturalacresoils.com/collections/all). The main chemical compositions of active essential oils are summarized in Table S1 based on manufacturer's GC-MS reports or literature. DMSO-soluble essential oils were dissolved in DMSO at $5 \%(\mathrm{v} / \mathrm{v})$. DMSO-insoluble essential oils were directly added to $S$. aureus cultures, then vortexed to form aqueous suspension [12]. The $5 \%$ essential oils or aqueous suspension were further diluted into the bacterial cultures to achieve desired dilution in the following drug exposure or MIC experiments to evaluate their activity against non-growing stationary phase or growing log phase S. aureus.

\section{Screening of essential oils for their activity against stationary phase $S$. aureus}

To evaluate the effect of essential oils on stationary phase bacteria, the essential oils and drugs were added to the 96-well plates containing stationary phase bacteria, leaving the first and last columns in each plate blank for control. Firstly, $20 \mu \mathrm{L} 5 \%$ essential oil stocks were added to the 96 -well plate containing $180 \mu \mathrm{L}$ of the overnight stationary phase $S$. aureus culture to obtain the desired concentration of $0.5 \%$. Then, the $0.25 \%$ treatment concentration was obtained by mixing $100 \mu \mathrm{L} 0.5 \%$ essential oil culture mixture with $100 \mu \mathrm{L}$ stationary phase culture. Finally, the $0.125 \%$ concentration was prepared as described above [12]. Tosufloxacin, 
ciprofloxacin, levofloxacin, rifampin, linezolid, vancomycin, sulfamethoxazole, trimethoprim, azithromycin and gentamicin were used at $50 \mu \mathrm{M}$ as control antibiotics. The plates were incubated at $37{ }^{\circ} \mathrm{C}, 5 \% \mathrm{CO}_{2}$ without shaking. After 3 days and 5 days of exposure to essential oils or drugs, the bacterial suspension was transferred to TSB plates with a 96-pin replicator to monitor the bacterial survival and regrowth after further incubation at $37^{\circ} \mathrm{C}$. All tests were run in triplicate.

\section{Antibiotic susceptibility test}

The minimum inhibitory concentrations (MICs) were determined using microdilution method according to the CLSI guideline [18]. Essential oils were 2-fold diluted from 1 to $0.0075 \%$. Gentamicin was 2-fold diluted from $512 \mu \mathrm{g} /$ $\mathrm{mL}$ to $0.25 \mu \mathrm{g} / \mathrm{mL}$ as a control antibiotic. The 96-well plates were sealed and incubated at $37^{\circ} \mathrm{C}$ overnight without shaking. Then the bacterial culture was observed to determine the MIC that inhibited the visible growth of $S$. aureus. All experiments were run in triplicate.

\section{Validation of active essential oils by colony forming unit (CFU) assay}

Based on the results of primary screening assay, active essential oils were further confirmed by colony forming unit (CFU) assay $[3,9,10,12]$. Briefly, the stationary phase bacteria were transferred into Eppendorf tubes for drug exposure experiment, which were treated with 0.25 and $0.125 \%$ active essential oils, respectively. Tosufloxacin, ciprofloxacin, levofloxacin, rifampin, linezolid, vancomycin, sulfamethoxazole, trimethoprim, azithromycin and gentamicin were added to bacterial suspensions at the final concentration of $20 \mu \mathrm{M}$, respectively. At different time points, $100 \mu \mathrm{L}$ bacterial suspensions were collected by centrifugation, washed and resuspended in PBS. After serial dilutions, $10 \mu \mathrm{L}$ of each dilution was plated on TSB plate for CFU count.

\section{Drug combination assay on stationary phase $S$. aureus}

In this study, we used Oregano as the common element to test the activity of various two-drug combinations in killing S. aureus Newman stationary phase cells. We evaluated tosufloxacin, levofloxacin, ciprofloxacin, rifampin, linezolid, vancomycin, sulfamethoxazole, trimethoprim, azithromycin and gentamicin at the final concentration of $5 \mu \mathrm{g} / \mathrm{mL}$ in combination with Oregano $(0.025 \%)$. The designed drug combinations or single drug controls were added directly to stationary phase culture. At each time point, the bacterial suspensions were collected by centrifugation and washed twice with PBS buffer. Then the cell suspension was serially diluted and plated on TSB agar plates for CFU counts as above. No drug added stationary phase culture was included as a drug-free control.

\section{Results}

Identification of active essential oils against stationary phase S. aureus

Consistent with our previous study [6], tosufloxacin was shown to have high activity against stationary phase $S$. aureus, while other clinical drugs including ciprofloxacin, levofloxacin, rifampin, linezolid, vancomycin, sulfamethoxazole, trimethoprim, azithromycin and gentamicin were not able to completely kill stationary phase $S$. aureus at $50 \mu \mathrm{M}$ after five-day drug exposure [8]. Interestingly, after three-day exposure, 30 (Cinnamon bark, Oregano, Thyme white, Lemongrass (Cymbopogon flexuosus), Bandit "Thieves", Sandalwood oil, Health shield, Allspice, Amyris, Palmarosa, Cinnamon leaf, Clove bud, Citronella, Geranium bourbon, Marjoram, Peppermint, Lemongrass (Cymbopogon citratus), Cornmint, Elemi, Ho wood, Head ease, Lemon eucalyptus, Litsea cubeba, Myrrh, Parsley seed, Coriander oil, Dillweed, Hyssop, Neroli, Rosewood oil), 6 (Cinnamon bark, Oregano, Thyme white, Bandit "Thieves", Lemongrass (Cymbopogon flexuosus), Sandalwood oil) and 7 (Cinnamon bark, Oregano, Thyme white, Lemongrass (Cymbopogon flexuosus), Allspice, Amyris, Palmarosa) essential oils were found to have high activity against stationary phase S. aureus at 0.5, 0.25 and $0.125 \%$ concentrations, respectively. When the drug exposure was extended to 5 days, additional 9 essential oils (Tea tree, Cajeput, Clove bud, Lavender, Sleep tight, Vetiver, Palo santo, Sage oil, Yarrow) and 4 essential oils (Health shield, Allspice, Amyris, Palmarosa) were found to be active at 0.5 and $0.25 \%$ concentration, respectively (Table 1 ). The top 10 essential oils (Cinnamon bark, Oregano, Thyme white, Lemongrass (Cymbopogon flexuosus), Bandit "Thieves", Sandalwood oil, Health shield, Allspice, Amyris, Palmarosa), which showed high activity at $0.25 \%$ concentration, were used in the subsequent testing to confirm their activity in inhibiting growth of S. aureus in MIC test and in CFU drug exposure assay for their activity against non-growing stationary phase $S$. aureus.

\section{MIC determination of the top active essential oils}

We carried out antibiotic susceptibility testing to determine the activity of the top 10 active essential oils against growing S. aureus. As shown in Table 2, Oregano, Amyris and Sandalwood oil were the most active agents in inhibiting the growth of $S$. aureus, with the lowest MIC of $0.015 \%$ in our study. The growth of $S$. aureus was efficiently suppressed by Cinnamon bark at $0.03 \%$. Allspice could inhibit the growth of $S$. aureus with an MIC of $0.06 \%$, while Thyme white, Health shield, Bandit "Thieves", Lemongrass (Cymbopogon flexuosus) and Palmarosa had the same MIC of $0.125 \%$ against $S$. aureus. Clinical drug gentamicin included as a control inhibited the growth of S. aureus with an MIC of $1 \mu \mathrm{g} / \mathrm{mL}$. 
Table 1 Effect of essential oils on stationary phase Staphylococcus aureus

\begin{tabular}{|c|c|c|c|c|c|c|c|}
\hline \multirow[t]{3}{*}{$\mathrm{EO}^{\mathrm{a}}$} & \multirow[t]{3}{*}{ Plant } & \multicolumn{6}{|c|}{ Viability of bacteria after 3 or 5 days of exposure ${ }^{\mathbf{b}}$} \\
\hline & & \multicolumn{2}{|c|}{$0.5 \% \mathrm{EO}^{\mathrm{a}}$} & \multicolumn{2}{|c|}{$0.25 \% \mathrm{EO}^{\mathbf{a}}$} & \multicolumn{2}{|c|}{$0.125 \% \mathrm{EO}^{\mathrm{a}}$} \\
\hline & & 3 days & 5 days & 3 day & 5 days & 3 day & 5 days \\
\hline Allspice & Pimenta officicalis & - & - & + & - & - & - \\
\hline Amyris & Amycris balsamifera & - & - & + & - & - & - \\
\hline Bandit "Thieves" & Synergy blend & - & - & - & - & + & + \\
\hline Cajeput & Melaleuca cajeputi & + & - & + & + & + & + \\
\hline Cinnamon bark & Cinnamomum zeylanicum & - & - & - & - & - & - \\
\hline Cinnamon leaf & Cinnamomum zeylanicum & - & - & + & + & + & + \\
\hline Citronella & Cymbopogon winterianus & - & - & + & + & + & + \\
\hline Clove bud & Eugenia caryophyllata & - & - & + & + & + & + \\
\hline Coriander oil & Coriandrum sativum & - & - & + & + & + & + \\
\hline Cornmint & Menta arvensis & - & - & + & + & + & + \\
\hline Dillweed & Anethum graveolens & - & - & + & + & + & + \\
\hline Elemi & Canarium iuzonicum & - & - & + & + & + & + \\
\hline Geranium bourbon & Pelargonium graveolens & - & - & + & + & + & + \\
\hline Clove Bud & Syzygium aromaticum & + & - & + & + & + & + \\
\hline Head ease & Synergy blend & - & - & + & + & + & + \\
\hline Health shield & Synergy blend & - & - & + & - & + & + \\
\hline Ho wood & Cinnamomum camphora & - & - & + & + & + & + \\
\hline Hyssop & Hyssopus officinalis & - & - & + & + & + & + \\
\hline Lavender & Lavendula officianalis & + & - & + & + & + & + \\
\hline Lemon eucalyptus & Eucalyptus citriadora & - & - & + & + & + & + \\
\hline Lemongrass & Cymbopogon citratus & - & - & + & + & + & + \\
\hline Litsea cubeba & Litsae cubeba & - & - & + & + & + & + \\
\hline Marjoram (Sweet) & Origanum marjorana & - & - & + & + & + & + \\
\hline Myrrh & Commiphora myrrha & - & - & + & + & + & + \\
\hline Neroli & Citrus aurantium & - & - & + & + & + & + \\
\hline Oregano & Origanum vulgare & - & - & - & - & - & - \\
\hline Palmarosa & Cymbopogon martinii & - & - & + & - & - & - \\
\hline Palo Santo & Bursera graveolens & + & - & + & + & + & + \\
\hline Parsley seed & Petroselinum sativum & - & - & + & + & + & + \\
\hline Peppermint & Mentha piperita & - & - & + & + & + & + \\
\hline Rosewood oil & Aniba rosaeodora & - & - & + & + & + & + \\
\hline Sage oil & Salvia officinalis & + & - & + & + & + & + \\
\hline Sandalwood oil & Santalum spicatum & - & - & - & - & + & + \\
\hline Sleep tight & Synergy blend & + & - & + & + & + & + \\
\hline Tea Tree & Melaleuca alternifolia & + & - & + & + & + & + \\
\hline Thyme white & Thymus zygis & - & - & - & - & - & - \\
\hline Vetiver & Vetiveria zizanoides & + & - & + & + & + & + \\
\hline Yarrow & Achillea millefolium & + & - & + & + & + & + \\
\hline
\end{tabular}

a "EO" essential oil

b "_-" No obvious colonies grew on TSB plate after drug exposure; " + " Obvious colonies were found on TSB plate after drug exposure 
Table 2 Activity of top 10 essential oils that are active against stationary phase Staphylococcus aureus in terms of their activity against growing bacteria (MIC) and non-growing bacteria in drug exposure

\begin{tabular}{|c|c|c|c|c|}
\hline \multirow{2}{*}{$\begin{array}{l}\text { Drug /essential } \\
\text { oil }\end{array}$} & \multirow[t]{2}{*}{ Plant } & \multirow{2}{*}{$\begin{array}{l}\text { MIC } \\
(\mu \mathrm{g} / \\
\mathrm{mL} \\
/ \%)\end{array}$} & \multicolumn{2}{|c|}{ Viability of bacteria after 3 or 5 days of EO ${ }^{\mathbf{b}}$ exposure $(0.25 \%)^{\mathbf{c}}$} \\
\hline & & & 3 day & 5 days \\
\hline Gentamicin $^{\text {a }}$ & - & 1 & + & + \\
\hline Sandalwood oil & Santalum spicatum & 0.015 & - & - \\
\hline Amyris & Amycris balsamifera & 0.015 & + & - \\
\hline Oregano & Origanum vulgare & 0.015 & + & - \\
\hline Cinnamon bark & Cinnamomum zeylanicum & 0.03 & - & - \\
\hline Allspice & Pimenta officicalis & 0.06 & + & - \\
\hline Thyme white & Thymus zygis & 0.125 & - & - \\
\hline Health shield & Cassia, clove, eucalyptus, lemon and rosemary & 0.125 & + & - \\
\hline Bandit "Thieves" & cloves, cinnamon, lemon, rosemary and eucalyptus & 0.125 & - & - \\
\hline Lemongrass & Cymbopogon flexuosus & 0.125 & - & - \\
\hline Palmarosa & Cymbopogon martinii & 0.125 & + & - \\
\hline
\end{tabular}

a The concentration of gentamicin used in drug exposure was $50 \mu \mathrm{M}_{;}{ }^{\mathrm{b}}$ "EO” essential oil; ${ }^{\mathrm{c}}$ “_" No obvious colonies grew on TSB plate after drug exposure; "+" Obvious colonies were found on TSB plate after drug exposure

\section{Comparison of active essential oils in their ability to kill stationary phase $S$. aureus}

We first tested the activity of tosufloxacin and other clinically used drugs against stationary phase $S$. aureus at $20 \mu \mathrm{M}$. As previously described [6], tosufloxacin could kill all stationary phase $S$. aureus cells after seven-day drug exposure, with no visible colonies on TSB agar plate. Levofloxacin, ciprofloxacin and rifampin had weak activity with $10^{4} \sim 10^{5} \mathrm{CFU} / \mathrm{mL}$ cells remaining after seven-day exposure. In contrast, other clinical drugs including linezolid, vancomycin, sulfamethoxazole, trimethoprim, azithromycin and gentamicin did not show obvious activity against stationary phase $S$. aureus even when the drug exposure was extended to 7 days (Fig. 1). In contrast, eight essential oils (Cinnamon bark, Oregano, Thyme white, Bandit “Thieves", Lemongrass (Cymbopogon flexuosus), Health shield, Allspice, Palmarosa) at $0.25 \%$ concentration could eradicate all stationary phase cells after one-day exposure. Meanwhile, Amyris could clear all the cells after three-day exposure whereas Sandalwood oil could not eradicate the stationary phase $S$. aureus cells after seven-day exposure. At a lower concentration of $0.125 \%$, we noticed that Oregano, Lemongrass (Cymbopogon flexuosus) and Thyme white still exhibited strong activity against stationary phase $S$. aureus, and no CFU could be detected after one-day exposure (Fig. 2). Meanwhile, Cinnamon bark, Allspice, Amyris and Palmarosa could eradicate stationary phase S. aureus cells after three-day exposure. On the other hand, Bandit "Thieves", Sandalwood oil and Health shield could not eradicate the stationary phase $S$. aureus culture even when exposure time was extended to 7 days.

\section{Development of essential oil drug combinations to} eradicate stationary phase $S$. aureus in vitro

It has been reported that synergistic activity between antibiotic and essential oil could occur, which achieved better bactericidal effect against growing S. aureus [19]. It is of great importance to include drugs that target persister bacteria in the treatment of infection diseases [7]. Based on our results, Oregano demonstrated high activity against not only log phase growing $S$. aureus with a low MIC but also stationary phase non-growing bacteria. Meanwhile, clinically used drugs had limited activity to kill $S$. aureus persisters. To more effectively eradicate the stationary phase $S$. aureus, we evaluated essential oil

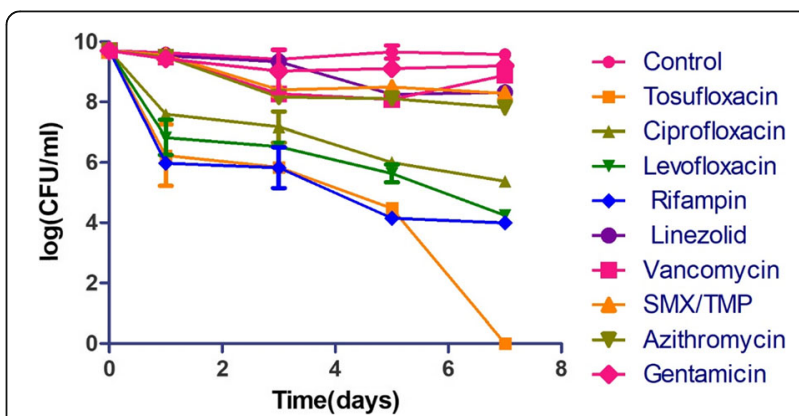

Fig. 1 Activity of tosufloxacin and commonly used antibiotics against stationary phase S. aureus. Tosufloxacin had good antipersister activity against $S$. aureus as expected, while antibiotics commonly used to treat $S$. aureus infections had poor activity against the stationary phase bacteria. The final concentration of antibiotics including tosufloxacin, ciprofloxacin, levofloxacin, rifampin, linezolid, vancomycin, sulfamethoxazole, trimethoprim, azithromycin and gentamicin, was all $20 \mu \mathrm{M}$. Sulfamethoxazoletrimethoprim is the combination of trimethoprim and sulfamethoxazole in a ratio of 5:1 


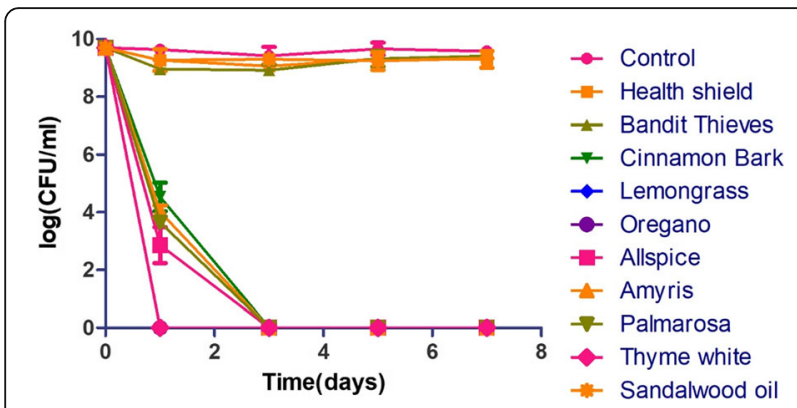

Fig. 2 Activity of active essential oil candidates (0.125\%) against stationary phase S. aureus. Oregano, Lemongrass (Cymbopogon flexuosus) and Thyme white could eradicate all stationary phase cells after one-day exposure. Cinnamon bark, Allspice, Amyris and Palmarosa could eradicate stationary phase $S$. aureus cells after three-day exposure. Bandit "Thieves", Sandalwood oil and Health shield still could not eradicate the $S$. aureus stationary phase culture even after five-day exposure drug combinations using clinical drugs in combination with Oregano $(0.025 \%)$. We found that some essential oil drug combinations were indeed much more effective than single drugs (Fig. 3). Among them, rifampin + Oregano could completely eradicate all the stationary phase S. aureus after just one-day exposure. Tosufloxacin + Oregano could eradicate all stationary phase cells after three-day exposure. Meanwhile, levofloxacin + Oregano and ciprofloxacin + Oregano could kill all the stationary phase $S$. aureus after five-day exposure. These drug combinations showed much better activity than respective single drugs $\left(10^{4} \sim 10^{6} \mathrm{CFU} / \mathrm{mL}\right.$ cells remaining) and somewhat better activity than Oregano alone $\left(10^{4} \mathrm{CFU} /\right.$ $\mathrm{mL}$ remaining). In contrast, other essential oil drug combinations such as linezolid + Oregano, vancomycin + Oregano, sulfamethoxazole + Oregano, trimethoprim + Oregano, azithromycin + Oregano and gentamicin + Oregano had limited activity against stationary phase cells, with $10^{4} \mathrm{CFU} / \mathrm{mL}$ bacterial cells remaining even

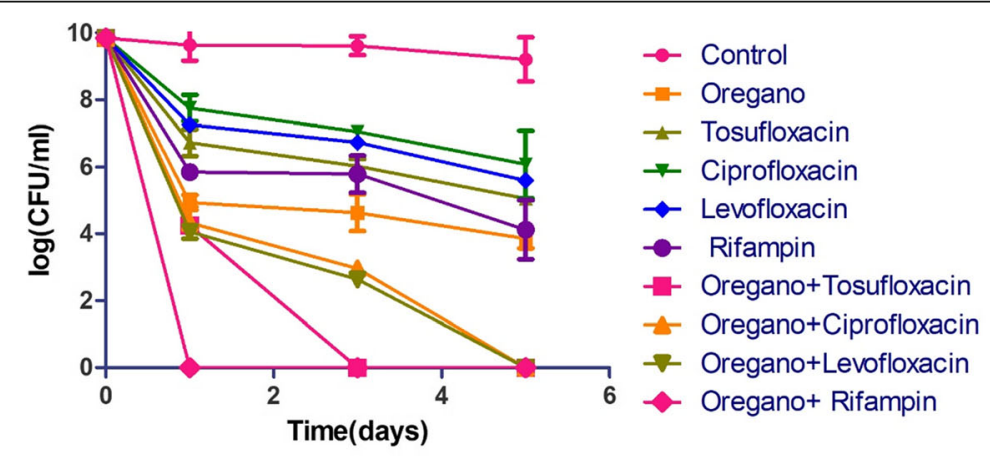

A

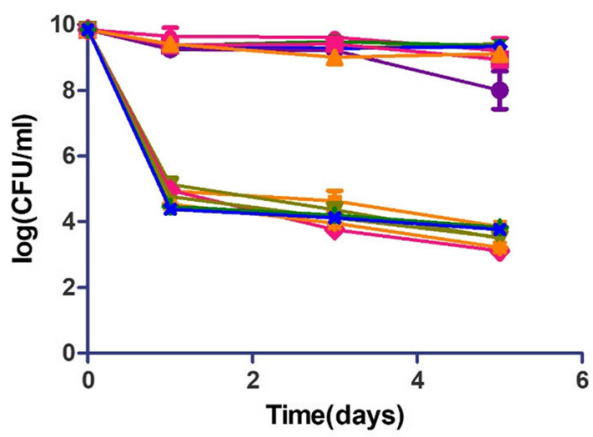

$\rightarrow$ Control

$\rightarrow$ Oregano

\pm Linezolid

$\rightarrow$ Vancomycin

$\rightarrow$ Sulfamethoxazole

- Trimethoprim

$\rightarrow$ Azithromycin

- Gentamicin

$\rightarrow$ Oregano+Linezolid

$\sim$ Oregano+Vancomycin

- Oregano+Sulfamethoxazole

B

$\rightarrow$ Oregano+Trimethoprim

+ Oregano+Azithromycin

* Oregano+Gentamicin

Fig. 3 Comparison of the activity of Oregano in combination with different antibiotics against stationary phase S. aureus. Effects of ciprofloxacin, levofloxacin, tosufloxacin, rifampin alone and their combinations with Oregano are presented in (A). Effects of linezolid, vancomycin, sulfamethoxazole, trimethoprim, azithromycin, gentamicin and their combinations with Oregano are presented in (B). The final concentration of antibiotics is $5 \mu \mathrm{g} / \mathrm{mL}$ and the concentration of Oregano is $0.025 \%$ 
after five-day exposure, suggesting these combinations were not significantly better than Oregano alone $\left(10^{4}\right.$ $\mathrm{CFU} / \mathrm{mL}$ remaining).

\section{Discussion}

$S$. aureus is known to give rise to a diverse range of infections from mild skin infections to serious diseases such as endocarditis and osteomyelitis and biofilm infections. Persisters are dormant phenotypic variants of bacterial cells that are tolerant to antibiotics and genetically identical drug susceptible kin [20]. Since persisters were first identified in 1944 [21], there is considerable evidence that drug-tolerant persisters are the contributors to persistent and relapsing infections [20, 22, 23], Meanwhile, treatment of persistent $S$. aureus infections has remained a challenge. It has been proposed that use of persister drugs against non-growing bacteria in combinations with antibiotics or drugs active against growing bacteria as in the Yin-Yang model can provide a more effective treatment of persistent infections [4]. Although a previous study has screened FDA-approved drug library to identify agents that have good activity against stationary phase $S$. aureus [6], only a few useful hits such as tosufloxacin and clinafloxacin were identified. Although ADEP4, an experimental acyldepsipeptide antibiotic killing $S$. aureus persisters in combination with rifampin has been reported to cure a deep wound infection in a mouse model [24], its validity in treating persistent $S$. aureus infections and in other persistent infection models remains to be confirmed. Thus, while it is of great importance to include drugs targeting persister bacteria in the treatment of $S$. aureus infections, the choice of persister drugs that may be useful is quite limited. Since most studies of essential oil activity on $S$. aureus were performed on log phase growing bacteria $[11,13]$, here we set out to determine the activity of a large panel of essential oils against stationary phase $S$. aureus cultures enriched in persister bacteria. Interestingly, we identified a range of essential oils, some of which are newly identified in this study, that have strong activity against stationary phase cultures of $S$. aureus that may be useful for more effective treatment of persistent $S$. aureus infections.

While there are some reports on activity of essential oils against $\log$ phase $S$. aureus, the number of evaluated essential oils is small (just one or two kinds of essential oils) $[11,14]$, and their activity against stationary phase $S$. aureus cultures has not been studied $[11,14]$. In this study, we evaluated a panel of 143 essential oils for their activity against stationary phase $S$. aureus. We identified 9 essential oils (at $0.25 \%$ concentration) that are more active than persister drug tosufloxacin $(20 \mu \mathrm{M})$, a quinolone drug control that could eradicate stationary phase S. aureus [6]. Among them, 7 essential oils (Oregano,
Cinnamon bark, Thyme white, Lemongrass (Cymbopogon flexuosus), Allspice, Amyris, Palmarosa) showed outstanding activity against stationary phase $S$. aureus at $0.125 \%$ concentration (Fig. 2 ). The MIC is used to measure activity of a compound against growing bacteria [25], however, compounds or drugs with low MICs do not translate into activity against non-growing bacteria. Interestingly, some essential oils have strong activity against both growing and non-growing bacteria. In this study, we found that the top 9 essential oils showed high activity against growing $S$. aureus with low MIC values (Table 2) also had good activity against non-growing stationary phase bacteria. Some of active essential oils such as Thyme white, Oregano, Cinnamon bark and Lemongrass (Cymbopogon flexuosus), have been reported to have high activity against $\log$ phase $S$. aureus in previous studies [13, 26-28], but we found these to be active against stationary phase $S$. aureus as well. More importantly, Bandit "Thieves", Health shield, Allspice, Amyris, Palmarosa were first reported in this study to have activity against both growing and non-growing stationary phase S. aureus. Compared with our previous work on activity of essential oils against stationary phase E. coli, some essential oils including Cinnamon bark, Oregano, Bandit "Thieves", Health shield and Allspice exhibited outstanding activity against both Gram-positive $S$. aureus and Gram-negative E. coli [29], while it seems that Thyme white, Lemongrass (Cymbopogon flexuosus), Amyris, Palmarosa just showed high activity against $S$. aureus [29], while Cinnamon leaf, Clove bud and Syzygium aromaticum were only active against $E$. coli [29]. Moreover, although some studies indicate that certain active essential oils including their main active components such as carvacrol or eugenol could induce membrane damage by causing loss of cellular contents $[15$, $30,31]$, there are limited studies available that focus on the active components and the mechanisms of antimicrobial action of essential oils in general. Here, we identified some active essential oils against stationary phase S. aureus and list their major compositions (Table S1). Further studies are needed to determine the main active components and the mechanisms of action of the active essential oils identified in this study.

Oregano is known to be one of the most effective essential oils against a wide variety of pathogens, including Pseudomonas sp., Salmonella sp., Escherichia coli and Borrelia burgdorferi $[10,13]$. In this study, Oregano exhibited high activity against $\log$ phase growing $S$. aureus strain Newman with a low MIC of $0.015 \%$, which was almost equal to the MIC value $(0.01 \%)$ for growing $S$. aureus strain ATCC 29213 [7]. Meanwhile, Oregano exhibited its high activity against stationary phase nongrowing bacteria with complete clearance without any regrowth at $0.125 \%$ concentration. Remarkably, when 
combined with some currently recommended antibiotics for $S$. aureus infections, Oregano showed a positive enhancement effect in increasing the activity of some antibiotics (quinolones, rifampin) against stationary phase $S$. aureus (Fig. 3). When combined with rifampin, the combination showed outstanding activity with $100 \%$ clearance after just one-day exposure. When combined with tosufloxacin and two other quinolone drugs (levofloxacin and ciprofloxacin), the combinations could wipe out all stationary phase cells after three-day or five-day exposure. The synergistic effect of Oregano and the four drugs may have implications for improved treatment of S. aureus persistent infections. Further studies should be carried out to confirm if such combination approaches are useful in animal models.

Additionally, we found Cinnamon bark, Thyme white, Lemongrass (Cymbopogon flexuosus), Allspice, Amyris and Palmarosa showed excellent activity against stationary phase $S$. aureus at a low concentration of $0.125 \%$ (Fig. 2). Cinnamon bark was reported to have activity against bacteria, fungi, inflammation, cancer and diabetes [32]. In this study, Cinnamon bark oil showed its remarkable activity against not only log phase growing $S$. aureus with a low MIC of $0.125 \%$ but also activity against non-growing stationary phase $S$. aureus. Thyme white, extracted from Thymus zygis, showed great activity against both $\log$ phase and stationary phase $S$. aureus at the same concentration of $0.125 \%$ (Table 1 and Table 2). Essential oils obtained from Thymus species were often compared for their antibacterial and antioxidant activity. And oil from Thymus zygis was the most active one against log phase Gram-positive and Gram-negative bacteria $[26,33]$. Our results highlighted its antibacterial activity not only against growing $S$. aureus bacteria but also non-growing stationary phase cells. The antibacterial effect of Thymus essential oils could be due to action of carvacrol or thymol or to a synergistic effect of its major and minor components [32]. The observation that three different Thymus species of the same genus all possessed activity against log phase bacteria and one of which was demonstrated to be active against stationary phase bacteria provides justification to identify the active components active against stationary phase bacteria. Lemongrass from two different plants (Cymbopogon flexuosus and Cymbopogon citratus) were evaluated in this study. While Lemongrass from Cymbopogon flexuosus could kill all stationary phase $S$. aureus in just 1 day at 0.125\%, Lemongrass from Cymbopogon citratus showed obvious activity only at a high concentration $(0.5 \%)$. This provides the basis for further identification of active component and testing of Cymbopogon flexuosus in animal models of infection. Allspice is widely known as a popular spice in food processing [34], here, its activity against $S$. aureus may facilitate its usage for antibacterial purpose. Compared with other essential oils, there are few studies discussing bioactivity of Amyris. One study revealed that vapor delivery of Amyris could alter pyrethroid efficacy and detoxification enzyme activity in mosquitoes [35]. Our new finding of Amyris activity on S. aureus may contribute to more bioactivity of Amyris and therapeutic use of Amyris balsamifera. Palmarosa, known as Cymbopogon martini, is used in Ayurvedic medicine to relieve nerve pain for skin problems and as a skin tonic in aromatherapy due to its antimicrobial properties [36]. While its immunomodulatory activity is based on geraniol [36], the main component of Palmarosa active against stationary phase $S$. aureus is unknown and will be determined in the future.

Along with the essential oils with strong activity against $S$. aureus persisters at $0.125 \%$, there were three essential oils (Bandit "Thieves", Sandalwood oil and Health shield) that showed obvious activity only at higher concentrations. Bandit "Thieves" and Health shield could eradicate all stationary phase cells after one-day exposure at $0.25 \%$ concentration. Both Bandit "Thieves" and Health shield are synergy blend of essential oils. While Bandit "Thieves" contains clove, cinnamon, lemon, rosemary and eucalyptus oils, Health shield is a mixture of essential oils from cassia, clove, eucalyptus, lemon and rosemary. They were active against growing S. aureus with the same MIC value of $0.125 \%$ and showed similar activity against non-growing stationary phase S. aureus cells (Table 2 and Fig. 2). Sandalwood oil exhibited obvious activity against both growing and non-growing $S$. aureus in our initial screen with 96-pin replicator transfer test at $0.25 \%$ (Table 2) but subsequent CFU assay revealed it showed activity only at a higher concentration of $0.5 \%$, presumably due to carry-over of the essential oil in the initial screen. Sandalwood oil in this study is obtained from Santalum spicatum (Australian Sandalwood). There are two other kinds of Sandalwood oil: East Indian Sandalwood oil extracted from Santalum album and New Caledonian Sandalwood oil prepared from the wood of Santalum austrocaledonicum [37]. Sandalwood oil from East Indian is widely studied as an attractive natural therapeutic for inflammatory skin diseases [38]. On the other hand, Sandalwood oil from Santalum spicatum has high commercial value for applications in aromatherapy and for the production of cosmetics such as soaps, creams and powder [37]. In this study, Sandalwood oil extracted from Santalum spicatum showed good activity against $S$. aureus, which demonstrated that it may be a promising antibacterial agent.

In this study, we carried out a high-throughput screen of essential oils for activity against stationary phase $S$. aureus and identified some highly active hits. While previous studies have identified some essential oils with activity against growing $S$. aureus, we identified additional 
new essential oils that have activity against both growing and non-growing stationary phase $S$. aureus. Since activity against non-growing bacteria seems to correlate with more effective treatment for persistent infections, the essential oils we identified that are highly active against non-growing stationary phase bacteria could be important for developing more effective treatment for persistent $S$. aureus infections. The potential limitations of the study include the mixed nature of the essential oils, lack of information on the active components of the active hits, lack of toxicity and pharmacokinetic data of the active essential oils in this study. The highly active essential oils form the basis for future studies to identify the active antimicrobial components and for further evaluation of the active hits in relevant animal models.

\section{Conclusions}

In summary, this is the first study of a large collection of 143 essential oils for activity against stationary phase $S$. aureus where we identified several promising essential oils. The top hits are Oregano, Cinnamon bark, Thyme white, Lemongrass (Cymbopogon flexuosus), Bandit "Thieves", Sandalwood oil, Health shield, Allspice, Amyris, Palmarosa. Meanwhile, we found in drug combination study with essential oil (Oregano) and antibiotics that some potent combinations such as Oregano plus quinolones or rifampin could effectively eradicate $S$. aureus persisters in vitro. Further studies should be carried out to identify the active components, evaluate safety, pharmacokinetics, and their activity to eradicate $S$. aureus persistent infections in animal models.

\section{Supplementary information}

Supplementary information accompanies this paper at https://doi.org/10. 1186/s12906-020-02898-4.

Additional file 1: Table S1. Chemical compositions of the most active essential oils against $S$. aureus

\section{Abbreviations}

CFU: Colony forming unit; CLSI: Clinical and laboratory standards institute; DMSO: Dimethyl sulfoxide; EO: Essential oil; MIC: Minimum inhibitory concentration; PBS: Phosphate-buffered saline; TSB: Tryptic soy broth

\section{Acknowledgements}

We thank Xiao Ma for helpful discussions on essential oil preparation. We thank Rong Quan for help with S. aureus culture. An earlier version of this manuscript was deposited as a preprint at bioRxiv [29].

\section{Authors' contributions}

Conceptualization, Y.Z.; Data curation, S.X.; and W.S.; Formal analysis, S.X.; and P.C.; Funding acquisition, Y.Z.; and S.X.; Resources, Y.Z.; Writing-original draft preparation, S.X.; Writing - review and editing, Y.Z. All authors have read and approved the manuscript.

\section{Funding}

Shuzhen Xiao was supported by Guangci Distinguished Young Scholars Program (GCQN-2017-C11). The funder had no role in the study design, data collection and analysis, decision to publish, or preparation of the manuscript.
Availability of data and materials

The data and materials supporting this study are available with the corresponding author upon request.

Ethics approval and consent to participate

Not applicable.

Consent for publication

Not applicable.

\section{Competing interests}

The authors declare that they have no competing interests.

\section{Author details}

${ }^{1}$ Department of Clinical Microbiology, Ruijin Hospital, Shanghai Jiao Tong University School of Medicine, Shanghai 200025, China. ${ }^{2}$ Department of Molecular Microbiology and Immunology, Bloomberg School of Public Health, Johns Hopkins University, Baltimore, MD 21205, USA.

Received: 16 November 2019 Accepted: 17 March 2020

Published online: 24 March 2020

\section{References}

1. Lowy FD. Staphylococcus aureus infections. N Engl J Med. 1998;12.

2. Sutcliffe CG, Grant LR, Reid A, Douglass GK, Weatherholtz RC, Hubler R, Quintana A, Reid R, Yazzie D, Santosham M, et al. The burden of Staphylococcus aureus among native Americans on the Navajo nation. PLoS One. 2019;14(3):e0213207.

3. Kahl BC, Becker K, Loffler B. Clinical significance and pathogenesis of staphylococcal small Colony variants in persistent infections. Clin Microbiol Rev. 2016;29(2):401-27.

4. Zhang Y. Persisters, persistent infections and the yin-Yang model. Emerg Microbes Infect. 2014;3(1):e3.

5. Van den Bergh B, Fauvart M, Michiels J. Formation, physiology, ecology, evolution and clinical importance of bacterial persisters. FEMS Microbiol Rev. 2017;41(3):219-51

6. Niu H, Cui P, Yee R, Shi W, Zhang S, Feng J, Sullivan D, Zhang W, Zhu B, Zhang Y. A clinical drug library screen identifies Tosufloxacin as being highly active against Staphylococcus aureus Persisters. Antibiotics (Basel). 2015:4(3):329-36.

7. Cui P, Niu H, Shi W, Zhang S, Zhang H, Margolick J, Zhang W, Zhang Y. Disruption of membrane by Colistin kills Uropathogenic Escherichia coli Persisters and enhances killing of other antibiotics. Antimicrob Agents Chemother. 2016;60(11):6867-71.

8. Yee R, Yuan Y, Tarff A, Brayton C, Gour N, Feng J, Shi W, Zhang Y: https:// www.biorxiv.org/content/https://doi.org/10.1101/686097v1.full;doi:https:// doi.org/https://doi.org/10.1101/686097, 2019.

9. Feng J, Li T, Yee R, Yuan Y, Bai C, Cai M, Shi W, Embers M, Brayton C, Saeki $\mathrm{H}$, et al. Stationary phase persister/biofilm microcolony of Borrelia burgdorferi causes more severe disease in a mouse model of Lyme arthritis: implications for understanding persistence, post-treatment Lyme disease syndrome (PTLDS), and treatment failure. Discov Med. 2019;27(148):125-38.

10. Feng J, Zhang S, Shi W, Zubcevik N, Miklossy J, Zhang Y. Selective essential oils from spice or culinary herbs have high activity against stationary phase and biofilm Borrelia burgdorferi. Front Med (Lausanne). 2017:4:169.

11. Bouhdid S, Abrini J, Zhiri A, Espuny MJ, Manresa A. Investigation of functional and morphological changes in Pseudomonas aeruginosa and Staphylococcus aureus cells induced by Origanum compactum essential oil. J Appl Microbiol. 2009;106(5):1558-68.

12. Ma X, Shi W, Zhang Y. Essential oils with high activity against stationary phase Bartonella henselae. Antibiotics. 2019;8(4):246.

13. Caillet $S$, Ursachi L, Shareck F, Lacroix M. Effect of gamma radiation and oregano essential oil on murein and ATP concentration of Staphylococcus aureus. J Food Sci. 2009:74(9):M499-508.

14. de Morais Oliveira-Tintino CD, Tintino SR, Limaverde PW, Figueredo FG, Campina FF, da Cunha FAB, da Costa RHS, Pereira PS, Lima LF, de Matos Y, et al. Inhibition of the essential oil from Chenopodium ambrosioides $L$. and alpha-terpinene on the NorA efflux-pump of Staphylococcus aureus. Food Chem. 2018;262:72-7. 
15. Feng J, Shi W, Miklossy J, Tauxe GM, McMeniman CJ, Zhang Y. Identification of Essential Oils with Strong Activity against Stationary Phase Borrelia burgdorferi. Antibiotics (Basel). 2018;7(4):1-14.

16. Yuan $Y$, Yee R, Gour N, Dong X, Feng J, Shi W, Zhang Y. https://www.biorxiv. org/content/https://doi.org/10.1101/686105v1.full;doi:https://doi.org/https:// doi.org/10.1101/686105, 2019

17. Feng J, Shi W, Zhang S, Sullivan D, Auwaerter PG, Zhang Y. A drug combination screen identifies drugs active against amoxicillin-induced round bodies of in vitro Borrelia burgdorferi Persisters from an FDA drug library. Front Microbiol. 2016;7:743.

18. Clinical and Laboratory Standards Institute. Performance Standards for Antimicrobial Susceptibility Testing; Seventeenth Informational Supplement. CLSI Doc M100-S17. 2007;27(1):154-61.

19. Buldain D, Buchamer AV, Marchetti ML, Aliverti F, Bandoni A, Mestorino N. Combination of Cloxacillin and essential oil of Melaleuca armillaris as an alternative against Staphylococcus aureus. Front Vet Sci. 2018;5:177.

20. Conlon BP, Rowe SE, Gandt AB, Nuxoll AS, Donegan NP, Zalis EA, Clair G, Adkins JN, Cheung AL, Lewis K. Persister formation in Staphylococcus aureus is associated with ATP depletion. Nat Microbiol. 2016;1(5):1-7.

21. Conlon BP. Staphylococcus aureus chronic and relapsing infections: evidence of a role for persister cells: an investigation of persister cells, their formation and their role in S. aureus disease. Bioessays. 2014;36(10):991-6.

22. Bojer MS, Lindemose $S$, Vestergaard $M$, Ingmer $H$. Quorum sensingregulated phenol-soluble Modulins limit Persister cell populations in Staphylococcus aureus. Front Microbiol. 2018;9:255

23. Guo L, Xu R, Zhao Y, Liu D, Liu Z, Wang X, Chen H, Kong MG. Gas plasma pre-treatment increases antibiotic sensitivity and Persister eradication in methicillin-resistant Staphylococcus aureus. Front Microbiol. 2018;9:537.

24. Mina EG, Marques CN. Interaction of Staphylococcus aureus persister cells with the host when in a persister state and following awakening. Sci Rep. 2016;6:31342.

25. Andrew JM. Determination of minimum inhibitory concentrations. J Antimicrob Chemother. 2001;48:11.

26. Afonso AF, Pereira OR, Valega M, Silva AMS, Cardoso SM. Metabolites and Biological Activities of Thymus zygis, Thymus pulegioides, and Thymus fragrantissimus Grown under Organic Cultivation. Molecules. 2018;23(7):1-15.

27. Song X, Sun Y, Zhang Q, Yang X, Zheng F, He S, Wang Y: Failure of Staphylococcus aureus to Acquire Direct and Cross Tolerance after Habituation to Cinnamon Essential Oil. Microorganisms 2019, 7(1):1-9.

28. Adukwu EC, Allen SC, Phillips CA. The anti-biofilm activity of lemongrass (Cymbopogon flexuosus) and grapefruit (Citrus paradisi) essential oils against five strains of Staphylococcus aureus. J Appl Microbiol. 2012;113(5): 1217-27.

29. Xiao S, Cui P, Shi W, Zhang Y. https://www.biorxiv.org/content/https://doi. org/10.1101/702951v1.full; doi: https://doi.org/https://doi.org/10.1101/ 702951, 2019.

30. Mith H, Clinquart A, Zhiri A, Daube G, Delcenserie V. The impact of oregano (Origanum heracleoticum) essential oil and carvacrol on virulence gene transcription by Escherichia coli 0157:H7. FEMS Microbiol Lett. 2015;362(1): $1-7$.

31. Teixeira B, Marques A, Ramos C, Serrano C, Matos O, Neng NR, Nogueira JM, Saraiva JA, Nunes ML. Chemical composition and bioactivity of different oregano (Origanum vulgare) extracts and essential oil. J Sci Food Agric. 2013:93(11):2707-14.

32. Han X, Parker TL. Antiinflammatory activity of cinnamon (Cinnamomum zeylanicum) bark essential oil in a human skin disease model. Phytother Res. 2017;31(7):1034-8.

33. Ballester-Costa C, Sendra E, Fernandez-Lopez J, Viuda-Martos M. Evaluation of the antibacterial and antioxidant activities of chitosan edible films incorporated with organic essential oils obtained from four Thymus species. J Food Sci Technol. 2016;53(8):3374-9.

34. Yilmaz S, Ergun S. Dietary supplementation with allspice Pimenta dioica reduces the occurrence of streptococcal disease during first feeding of Mozambique Tilapia fry. J Aquat Anim Health. 2014;26(3):144-8.

35. O'Neal ST, Johnson EJ, Rault LC, Anderson TD. Vapor delivery of plant essential oils alters pyrethroid efficacy and detoxification enzyme activity in mosquitoes. Pestic Biochem Physiol. 2019;157:88-98.

36. Murbach Teles Andrade BF, Conti BJ, Santiago KB, Fernandes Junior A Sforcin JM. Cymbopogon martinii essential oil and geraniol at noncytotoxic concentrations exerted immunomodulatory/anti-inflammatory effects in human monocytes. J Pharm Pharmacol. 2014;66(10):1491-6.
37. de Groot AC, Schmidt E. Essential oils, part Vl: sandalwood oil, Ylang-Ylang oil, and jasmine absolute. Dermatitis. 2017;28(1):14-21.

38. Sharma M, Levenson C, Clements I, Castella P, Gebauer K, Cox ME. East Indian sandalwood oil (EISO) alleviates inflammatory and proliferative pathologies of psoriasis. Front Pharmacol. 2017;8:125.

\section{Publisher's Note}

Springer Nature remains neutral with regard to jurisdictional claims in published maps and institutional affiliations.
Ready to submit your research? Choose BMC and benefit from:

- fast, convenient online submission

- thorough peer review by experienced researchers in your field

- rapid publication on acceptance

- support for research data, including large and complex data types

- gold Open Access which fosters wider collaboration and increased citations

- maximum visibility for your research: over $100 \mathrm{M}$ website views per year

At $\mathrm{BMC}$, research is always in progress.

Learn more biomedcentral.com/submissions 